\title{
Effect of colony size and age on resource allocation between growth and reproduction in the corals Goniastrea aspera and Favites chinensis
}

\author{
Sayaka Kai* ${ }^{*}$ Kazuhiko Sakai \\ Sesoko Station, Tropical Biosphere Research Center, University of the Ryukyus, 3422 Sesoko, Motobu, \\ Okinawa 905-0227, Japan
}

\begin{abstract}
The effect of colony size and age on growth and sexual reproduction was examined by taking small-sized fragments from large mature donor colonies of Goniastrea aspera and Favites chinensis. Both species are massive colonial corals in the family Faviidae. Monopolyp and oligopolyp ( 5 to 8 polyps) fragments were established. The fragments were cultured in running seawater aquaria for 22 mo, and growth and gamete production were measured. In both species, monopolyp fragments had higher growth rates than oligopolyp fragments. F. chinensis had higher growth rates than G. aspera in both fragment sizes. Polyps tended to bud when there was open space, and smaller colonies had higher growth rates, probably because the polyps of smaller colonies had more open space. In G. aspera, both the monopolyp and oligopolyp fragments produced gametes, whereas in $F$. chinensis, neither type of fragment produced gametes. These results suggest that sexual maturity is determined by colony age in G. aspera and by colony size in F. chinensis. Our results also suggest that polyps are integrated at the colony level. Polyp integration activity in a colony may be determined by the age of the colony in G. aspera and by the size of the colony in F. chinensis, likely maximizing colony fitness.
\end{abstract}

KEY WORDS: Resource allocation $\cdot$ Colonial corals $\cdot$ Growth $\cdot$ Reproduction $\cdot$ Colony size $\cdot$ Colony age $\cdot$ Integration

Resale or republication not permitted without written consent of the publisher

\section{INTRODUCTION}

Colonial corals are composed of interconnected building modules (polyps), which are ultimately derived by asexual budding from a common larval ancestor that was a product of sexual reproduction (Hughes \& Connell 1987). A colony can survive when some polyps in the colony die. Therefore, partial mortality of a colony occurs in colonial corals and distorts the positive relationship between colony size and colony age, the latter being measured as time since the establishment of the first polyp of a colony (Hughes \& Jackson 1980, 1985). As a result, estimating colony age from colony size is difficult in colonial animals (Babcock 1991, Muko et al. 2001, Bone \& Keough 2005). In contrast to studies on solitary animals, therefore, aspects of age dependence in population dynamics and life histories have been less studied in colonial animals. Instead, colony size has been believed to be more important in understanding the population dynamics and life histories of colonial corals (Hughes \& Jackson 1980, 1985). However, several studies have suggested the importance of the combined effects of colony size and age (e.g. Hughes \& Connell 1987). To more precisely reveal the effects of colony age and size on life history traits, further experimental analyses are required.

Colonial corals can be divided into fragments that can then survive and grow. By taking fragments of different sizes from a donor colony, colonies of the same age but of different size can be experimentally established (e.g. Okubo et al. 2007). Connell (1973) proposed that the relative importance of colony size on energy allocation 
to the productions of gametes could be tested by dividing a large mature colony into smaller fragments of different sizes. To date, this method has been employed in 2 studies on faviid corals. One study of Goniastrea favulus found that colony size was primarily responsible for the onset of gametogenesis, but colony age also influenced polyp fecundity (Kojis \& Quinn 1985). The other study, on Montastrea annularis, demonstrated that only colony size affected the ability of colonies to reproduce sexually (Szmant-Froelich 1985). These 2 studies suggest that colony age and size affect sexual reproduction in some coral species, while only colony size matters in others. Whether polyps of a colonial coral are integrated at the colony level may also be tested by experimentally changing colony size. Two views exist about the integration of polyps in colonial corals: the polyps respond individually just to their microenvironment (e.g. Soon \& Lang 1992), and polyp function is integrated at the colony level (e.g. Loya 1976b).

To examine the effects of colony age and size on the life history traits of colonial corals, the survival and growth of colonies should be followed in addition to sexual reproduction. Organisms allocate their resources to major life history traits (i.e. survival, growth, and reproduction) to maximize their fitness (e.g. Sibly \& Calow 1986). Traditional life history theories often focus on an organism's age at maturity, since this is pivotal in life history evolution (Roff 1992, Stearns 1992). Other things being equal, earlier reproduction represents greater fitness, but when survival is high, the benefits of larger size begin to predominate. Therefore, in Goniastrea favulus, which produced gametes even when colony size was reduced (Kojis \& Quinn 1985), growth of the fragments (i.e. the average budding rate of polyps constituting the fragment) may have decreased. In contrast, in Montastrea annularis, which did not produce gametes when the colony size was reduced (Szmant-Froelich 1985), growth may not have been reduced. Unfortunately, both studies only quantified sexual reproduction and not growth.

Our study was undertaken to address 2 goals. Our first aim was to determine the relative importance of colony size and colony age on sexual reproduction in faviid corals. The second purpose was to reveal the pattern of resource allocation between growth and sexual reproduction using experimentally generated fragments. To address these questions, we took small-sized fragments from large, mature donor colonies and measured the growth (increase in polyp number) and gamete production of the fragments. The fragments are considered small colonies in this study, but the colony age is older than for same-sized colonies produced naturally by sexual reproduction (Szmant-Froelich 1985).

We focused on 2 colonial coral species, Goniastrea aspera and Favites chinensis, both of which are com- mon in intertidal habitats in Okinawa, Japan (K. Sakai unpubl. data). These 2 faviid corals are morphologically similar (Veron 2000). Both exhibit a massive colonyform cerioid polyp arrangement. The budding of the polyps in the central part of the colony is intratentacular (Nishihira \& Veron 1995). One apparent difference between the 2 species in the field is their colony size, which is an important species-specific character that correlates with many reproductive traits (Soong 1993). The maximum mean diameter of $G$. aspera colonies is $\approx 50 \mathrm{~cm}$, while that of $F$. chinensis colonies is $>100 \mathrm{~cm}$ at our study sites. The maturation colony size of $G$. aspera is 60 polyps at the study site (Sakai 1998a), but there are no data for $F$. chinensis, since small colonies are very rare at the study site (K. Sakai unpubl. data). Because colony size is expected to affect other life history traits, such as resource allocation between growth and reproduction, we explored the effect of speciesspecific size differences on the life history traits of 2 species co-occurring in a similar physical environment.

\section{MATERIALS AND METHODS}

Experimental settings. Samples were taken from 10 large mature colonies of Goniastrea aspera from Bise and 10 colonies of Favites chinensis from Sesoko, Okinawa, southern Japan, using a hammer and chisel. Each colony was divided into 4 fragments of 2 sizes: 2 monopolyp fragments, and 2 oligopolyp (with 5 to 8 polyps) fragments. In total, 20 monopolyp and 20 oligopolyp fragments were prepared from 10 donor colonies for each species. The fragments were cut from nonmarginal positions on the donor colonies because marginal polyps are nonreproductive (Hall \& Hughes 1996, Sakai 1998a). In the oligopolyp fragments, 1 nonmarginal polyp was entirely surrounded by 4 to 7 marginal polyps. The fragments were transplanted onto limestone plates $(15 \times 12 \times 3 \mathrm{~cm})$. Fragments were fixed in holes drilled into the limestone plates with underwater epoxy glue (Konishi Underwater Epoxy E380). The diameter of each hole was slightly larger than the diameter of the fragments, and the height of all fragments was almost the same on all plates.

One monopolyp fragment and 1 oligopolyp fragment from each of 2 donor colonies of the same species were transplanted onto the same plate. The combination of the donor colonies was haphazardly determined. We made a total of 80 fragments from 10 colonies of 2 species. The fragments were held in a tank with unfiltered running seawater at Sesoko Station, University of the Ryukyus, Japan.

Growth and sexual reproduction. We counted the number of polyps in the fragments at monthly intervals from 17 August 2003 to 7 June 2005. We used the polyp 
budding rate to assess fragment growth. The growth rate was calculated as (number of new polyps)/(initial number of polyps). When polyps were newly formed, intra- or extratentacular budding mode was recorded.

Spawning of Goniastrea aspera and Favites chinensis occurs between 21:00 h and 23:00 h, 3 to $5 \mathrm{~d}$ and 5 to $7 \mathrm{~d}$ after the full moon in June and July, respectively in Okinawa (Heyward et al. 1987, Hayashibara et al. 1993, Sakai 1997). We observed spawning of fragments of both species from $1 \mathrm{~d}$ before to $2 \mathrm{~d}$ after the predicted dates of spawning in 2004. Five of 10 plates were randomly selected for each species; each plate was placed in an individual bucket filled with seawater at 19:00 h. At 24:00 h, the buckets were examined for gametes. Five large mature colonies of each species were collected from the reefs at the same location where the donor colonies had been collected 6 to $9 \mathrm{~d}$ before the initiation of spawning in each month. The mature colonies were placed in a holding tank, and their spawning activity was monitored.

To assess egg production, all fragments were fixed in $10 \%$ formalin in seawater 2 to $4 \mathrm{~d}$ before the predicted date of spawning in 2005. The fragments were fixed in formalin for at least $24 \mathrm{~h}$ and decalcified in a solution of $5 \%$ formalin $+5 \%$ formic acid. The decalcified fragments were preserved in $70 \%$ alcohol. In addition to the fragments, about 20 polyps were cut from 5 mature colonies collected from the field 2 to $4 \mathrm{~d}$ before the predicted date of spawning. These polyps were cut from nonmarginal positions on the donor colonies (see 'Experimental settings'). These polyps from the field were processed in the same way as the experimental fragments. The polyps were cut from decalcified specimens. For each polyp, the maximum and minimum diameters at the oral side and the height were measured to the nearest $0.1 \mathrm{~mm}$. Polyp volume, which was assumed to represent polyp somatic biomass, was estimated as $k \times \pi \times$ (maximum diameter/2) $\times$ (minimum diameter/2) $\times$ height, where $k$ ranged from $1 / 3$ (conical) to 1 (cylindrical). The value of $k$ was subjectively determined for each polyp according to its shape. Each polyp was dissected under a binocular dissecting microscope, and the number of mesenteries per polyp was recorded. Gonad volume was estimated for 5 randomly selected mesenteries in each polyp. The gonads of both species were elliptical. The pro- jected area of the gonad was measured from an image taken with a digital camera mounted on a stereoscopic microscope. The image was transferred to a computer, and the area was measured using Sigma Scan Pro (SPSS). Gonad height was measured with a micrometer under a stereoscopic microscope. The volumes of the gonads were estimated as (projecting area) $\times$ (height of gonad). Fecundity was quantified as (estimated total volume of gonad per polyp)/(estimated polyp volume). Although all polyps of the fragments were divided from nonmarginal positions on the donor colonies, the polyps were grouped according to their positions on the fragments. The groups were designated as (1) OM, polyps that were originally marginal on the experimental fragment, (2) OI, polyps that were originally interior in the experimental fragment, (3) BM, polyps that budded after the fragments were cut and were marginal on the experimental fragment at the end of experiment, and (4) BI, polyps that were budded after the fragments were cut, and were interior on the experimental fragment at the end of the experiment (Fig. 1). Only OM polyps were used to analyze
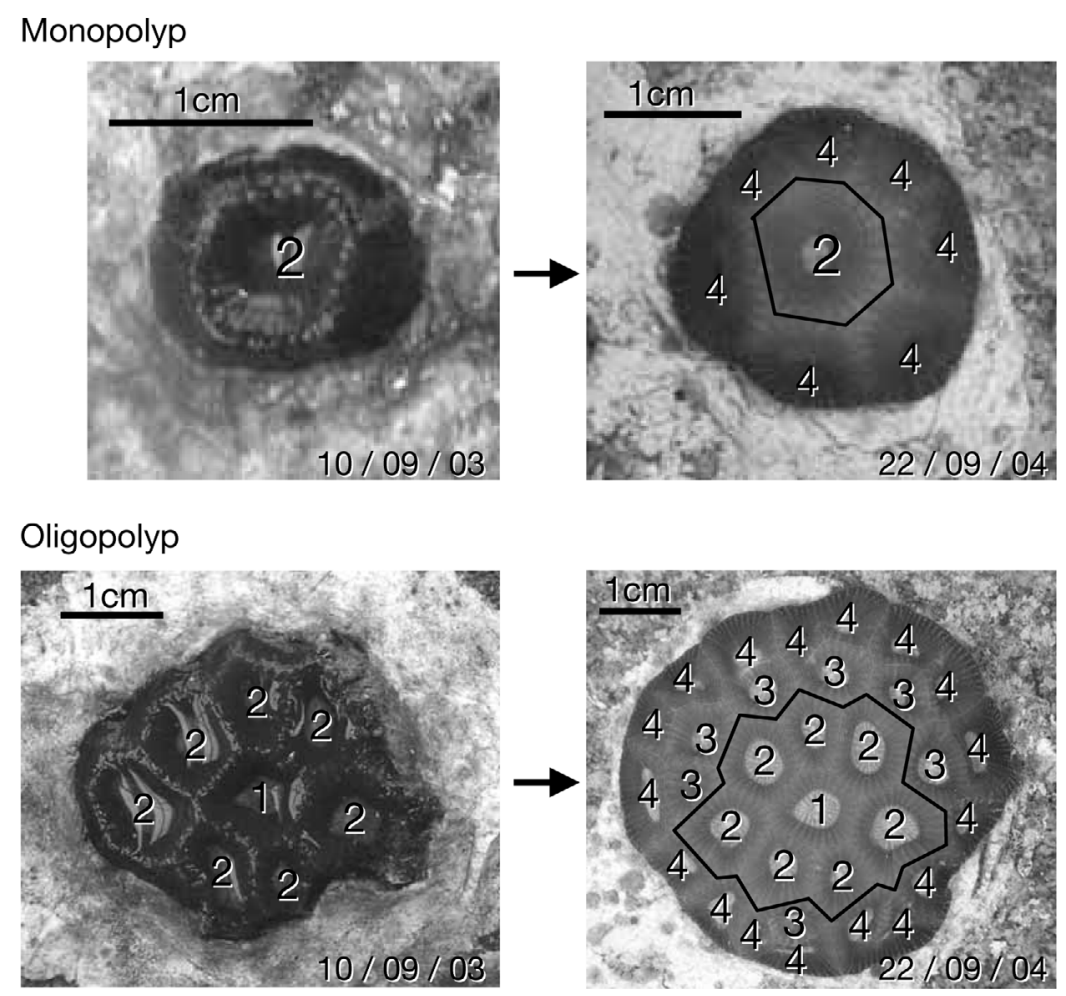

Fig. 1. Favites chinensis. Photographs (with dates: dd/mm/yy) showing the positions of polyps in monopolyp (top) and oligopolyp (bottom) fragments. The date $(\mathrm{dd} / \mathrm{mm} / \mathrm{yy})$ the picture was taken is shown in the bottom right corner of the photograph. 1: interior when transplanted $(\mathrm{OI})$; 2 : marginal when transplanted (OM); 3: budded after transplant and nonmarginal (BI); 4: budded after transplant and marginal (BM). The solid lines in the right-hand panels enclose polyps that were present when the transplant was initiated 
fecundity, because the polyps play different roles according to their positions within a colony (Sakai 1998a).

Statistical analyses. Because of mortality, the number of surviving fragments derived from the same donor colony varied at the end of the experiment, which caused the data to be unbalanced. To avoid pseudoreplication, we calculated mean growth rate and mean gamete production across (if any) 2 fragments derived from the same donor colony, and used the means for monopolyp and oligopolyp fragments from the same donor colony as the experimental unit in the following analyses (see Hurlbert 1984). We analyzed mean growth rate as a split-plot design with Species (Goniastrea aspera versus Favites chinensis) as the between-subject factor, Size (initial colony size; monopolyp versus oligopolyp) as the within-subject factor, and Colony nested within Species as a random effect. Due to mortality, some cells in our data set are empty in the sense that all same-sized fragments from some colonies died in the course of the experiment, and thus moment-based methods of analysis could not be used to test our hypotheses of interest (Searle 1987). Instead, we used the residual maximal likelihood (REML) method, which is effective for data sets with some random empty cells (Little \& Rubin 1987). Similarly, mean gamete production for $G$. aspera was analyzed with a 2-way crossed ANOVA, with Size as a fixed factor and Colony as a random effect based on the REML method.

In the growth rate of a monopolyp fragment of Goniastrea aspera, an outlier was detected using Grubbs' test ( $p<0.05$; Grubbs 1969, Stefansky 1972); this outlier was not included in the analysis (see Fig. 2, arrow).

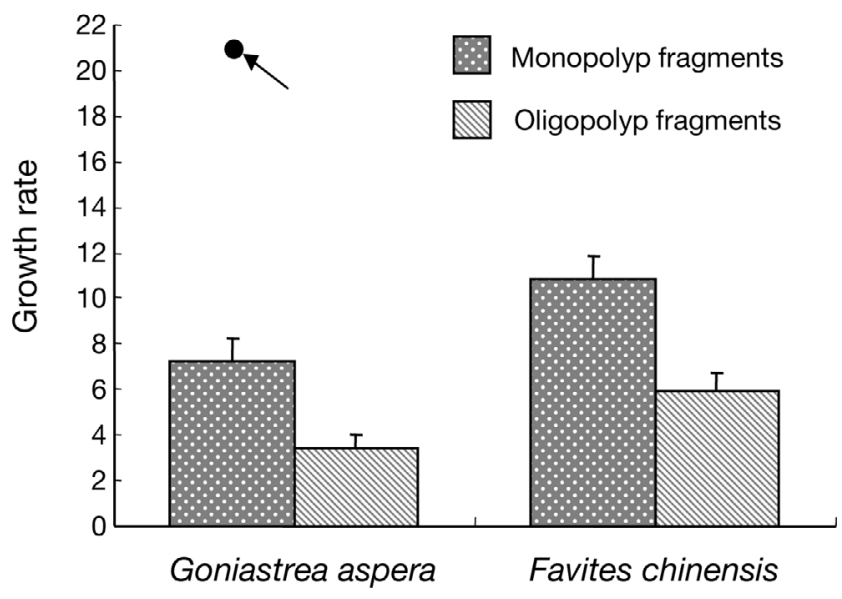

Fig. 2. Goniastrea aspera and Favites chinensis. Adjusted growth rates (mean $\pm \mathrm{SE}$ ) of monopolyp and oligopolyp fragments over 22 mo. Arrow indicates outlier. (see 'Materials and methods' for more details)

\section{RESULTS}

\section{Growth rate}

Monopolyp fragments had significantly higher growth rates than oligopolyp fragments, and Favites chinensis had significantly higher growth rates than Goniastrea aspera regardless of the initial fragment size (Fig. 2). Both main effects were significant, although the Species $\times$ Size interaction was nonsignificant (Table 1).

\section{Mode of budding}

The mode of budding in relation to the original polyp positions at the start of the experiments was analyzed using the data collected from August 2003 to October 2004 , because the original position of polyps was difficult to assign after October 2004 due to the large number of polyps. OI polyps of oligopolyp fragments did not bud in either species during the period. However, in both species, OM polyps in the oligopolyp fragments exhibited both modes of budding. In Goniastrea aspera and Favites chinensis, OM polyps budded both extraand intratentacularly - G. aspera: number of extratentacular buddings per polyp $=1.78 \pm 0.27$, intratentacular $=0.80 \pm 0.23 ; F$. chinensis: extratentacular $=3.13 \pm$ 0.26 , intratentacular $=1.26 \pm 0.66$.

\section{Spawning}

In 2004, spawned eggs occurred at the surface of all 5 buckets of Goniastrea aspera, in which 5 randomly selected experimental plates were placed, respectively, but eggs were found in only 1 bucket of Favites chinensis. The frequency of spawning on the experimental plates was higher in G. aspera than in F. chinensis (Fisher's exact test, $\mathrm{p}=0.048$ ). In contrast, all large mature colonies of both species collected from the field spawned.

Table 1. Goniastrea aspera and Favites chinensis. ANOVA for growth rates

\begin{tabular}{|lcccc|}
\hline Source & df & $F$ & SS & $p$ \\
\hline Species & 1,15 & 8.56 & 19.28 & $0.0105^{\mathrm{a}}$ \\
Colony [Species] & 15,5 & - & 46.28 & - \\
Size & 1,5 & 36.56 & 82.38 & 0.0018 \\
Species $\times$ Size & 1,5 & 0.58 & 1.30 & 0.48 \\
& & & & \\
aNot significantly different if outlier is not removed \\
bandom effect
\end{tabular}




\section{Gamete production}

In Goniastrea aspera, both the fragments and the colonies collected from the field had eggs in their polyps, while only the field-collected colonies of Favites chinensis contained eggs. Therefore, gamete production could only be analyzed for $G$. aspera.

Total gonad volume of a polyp/polyp volume was not significantly different between the monopolyp and oligopolyp fragments for OM polyps (Table 2, Fig. 3).

\section{DISCUSSION}

We found that polyp budding mode and rate were affected by the availability of open space around the polyps for both Goniastrea aspera and Favites chinensis. In G. aspera, all budding in nonmarginal polyps was intratentacular, and $96 \%$ of the budding in marginal polyps was extratentacular (Sakai 1998a). In the present study, all polyps of the transplanted fragments were taken from nonmarginal positions on the donor colonies. Therefore, we expected that all polyps would exhibit intratentacular budding if they maintained their original budding mode. However, OM polyps exhibited both intra- and extratentacular budding. In the oligopolyp fragments, OM polyps budded, but OI polyps did not. Furthermore, the monopolyp fragments had significantly higher growth rates than the oligopolyp fragments. OI polyps in the oligopolyp fragments were completely surrounded by isogenic polyps, while

Table 2. Goniastrea aspera. ANOVA for total gonad volume of a polyp/polyp volume

\begin{tabular}{|lcccc|}
\hline Source & df & $F$ & SS & $p$ \\
\hline Colony $^{\mathrm{a}}$ & 9,4 & - & 0.011 & - \\
Size & 1,4 & 2.23 & 0.0024 & 0.21 \\
aRandom effect & & & & \\
\hline
\end{tabular}

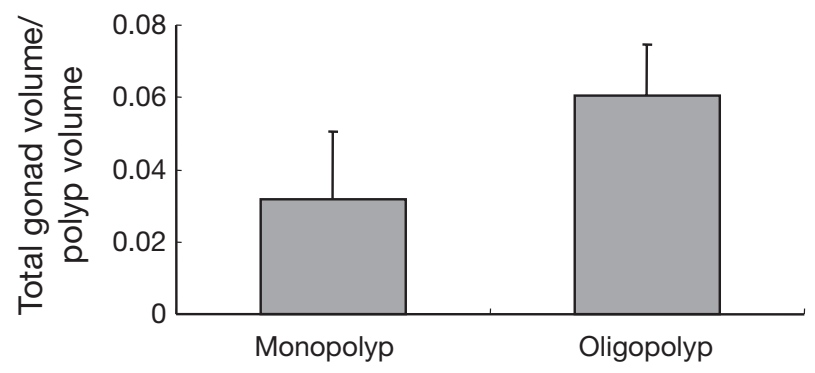

Fig. 3. Goniastrea aspera. Adjusted mean $( \pm \mathrm{SE})$ of total gonad volume/polyp volume of OM (marginal when transplanted) polyps of monopolyp and oligopolyp fragments
OM polyps in the oligopolyp fragments and the monopolyp fragments had open space around them. Thus, the availability of open space affected not only the budding mode but also the growth rate. A similar pattern was observed for $F$. chinensis, and the relationship between the availability of open space and budding mode appears to be the same as for $G$. aspera. In the Red Sea faviid coral Favia favus, polyp budding was initiated after a polyp reached an allometric threshold ratio of 2 stereotypic landmarks consisting of the surface area of the polyp and its perimeter (Gateno \& Rinkevich 2003). Although we did not measure polyp allometry, we argue that the availability of open space is also crucial for polyps to initiate budding.

Smaller colonies of Goniastrea aspera and Favites chinensis have higher colony growth rates, since polyps bud when there is open space, and polyps of smaller colonies face more open space. In colonial corals, the relative colony growth rate decreases with increasing colony size (Connell 1973, Loya 1976a, Hughes \& Jackson 1985, Hughes \& Connell 1987, Sakai 1998b). This negative correlation between colony size and colony growth rate can be explained by the mechanism that polyps bud when there is open space around them. In massive colonial corals such as G. aspera and F. chinensis, as colony size increases, the ratio of marginal to nonmarginal polyps decreases. Although marginal polyps may have space for budding when the colonies grow into massive forms, the proportion of polyps that face open space decreases in large colonies. Therefore, the average budding rate for polyps decreases in large colonies. The budding rate of polyps was affected by the availability of open space around the individual polyps, but we do not consider that the polyps only respond to their microenvironment. Rather, we argue that the polyps' response to open space is a mechanism the polyps employ to increase the fitness of the colony. Generally, mortality of whole colonies is high when corals are young and small (Connell 1973, Hughes \& Jackson 1980, 1985, Hughes \& Connell 1987, Babcock 1991, Sakai 1998b, Smith \& Hughes 1999). However, small colonies can grow rapidly by adopting the mechanism at the polyp level. Rapid growth of small colonies confers a selective advantage of escaping whole-colony mortality, which is generally high when the colonies are small (Kojis \& Quinn 1981, Szmant 1986, Soong 1993).

Our results suggest that sexual maturity is determined by colony age in Goniastrea aspera, but by colony size in Favites chinensis. In G. aspera, both monopolyp and oligopolyp fragments produced gametes. Intact colonies of $G$. aspera mature at 60 polyps in Okinawa (Sakai 1998a). In our study, fragments of $G$. aspera as small as 3 polyps produced gametes. Thus, fragments of $G$. aspera produced 
gametes even though they were much smaller than the normal maturation size of intact colonies. These results indicate that the polyps of $G$. aspera allocate resources to gamete production and budding after the colony reaches the age of sexual maturity, irrespective of colony size. On the other hand, in F. chinensis, neither the monopolyp nor the oligopolyp fragments produced any gametes in the second year. Although the experimental fragments of $F$. chinensis did not spawn, possibly because this species may be more sensitive to experimental manipulation and the aquarium environment than G. aspera, we suggest that polyps of smallsized fragments of $F$. chinensis taken from mature colonies did not allocate resources to gamete production, but rather to budding. This hypothesis can be tested by studying fragments of various sizes in F. chinensis. Nonetheless, our hypothesis suggests that F. chinensis polyps allocate resources to gamete production only after the colony reaches the size of sexual maturity, and if the colony size is reduced by fragmentation, polyps stop allocating resources to gamete production and allocate them to growth irrespective of colony age. In other words, if our hypothesis is correct, resource allocation to sexual reproduction and growth is reversible in F. chinensis, but not in G. aspera. Mean colony sizes of $F$. chinensis are larger than those of G. aspera in the field (K. Sakai unpubl. data). For reefflat species such as $G$. aspera and F. chinensis, the probability of partial mortality by exposure during low tides is higher for larger colonies, because larger colonies are exposed more frequently and for longer periods of time (Babcock 1991). Hence in F. chinensis, reversible resource allocation would be advantageous, because this species could grow rapidly by allocating all resources to budding when a colony becomes smaller due to partial mortality.

Our results suggest that polyp function is integrated into the fitness of the colonies in both Goniastrea aspera and Favites chinensis. Controversy has existed over whether polyp function is integrated at the colony level, and the 2 views in this debate are that polyp function is mainly determined by responses to the microenvironment, or that the function of a polyp is integrated at the colony level. As an example of the former view, Soong \& Lang (1992) suggested that sexual reproduction of polyps was not integrated at the colony level, but was determined at the polyp level alone in faviid corals. In contrast to this view, oriented translocation of photosynthetic materials among polyps within a colony, i.e. intra-colonial transport of ${ }^{14} \mathrm{C}$-labeled photosynthetic products towards regenerating areas ('sinks'), was experimentally confirmed in the massive corals Favia favus, Platygyra lamellina (Oren et al. 1997), Porites sp. (Oren et al. 1998), Lobophyllia corymbosa (Brickner et al. 2006), and in the encrusting coral Oculina patagonica (Fine et al. 2002). Our study supports the latter view. In G. aspera, allocation of resources to gamete production was determined by colony age, not by colony size. Polyps may be integrated at the level of a colony through age-dependent patterns of resource allocation. In contrast, in F. chinensis, allocation of resources to gamete production appeared to be determined by colony size, not by colony age. No polyps in the fragments of $F$. chinensis produced any eggs. If a polyp's allocation of resources to gamete production is determined by its microenvironment alone, the nonmarginal polyps of $F$. chinensis should have been producing gametes, because these polyps did not face open space and hence did not bud. It is possible that the resources of nonmarginal polyps were orientationally translocated to the marginal polyps, and the marginal polyps budded, using the resources for growth at the expense of gamete production. The higher growth rate of $F$. chinensis compared to $G$. aspera may be the result of the translocation of resources from nonmarginal to marginal polyps.

This study suggests that resource allocation between growth and gamete production is determined by different mechanisms in Goniastrea aspera and Favites chinensis. In G. aspera, resource allocation was determined by colony size and colony age, while in F. chinensis resource allocation was affected by colony size alone. The apparent ecological difference between these 2 species is their colony size, and colony size is expected to affect life history traits. A comparison of life history strategies between these 2 species would reveal adaptations to the same habitat by using different mechanisms of resource allocation.

Acknowledgements. We are indebted to the staff of Sesoko Station, Tropical Biosphere Research Center, University of the Ryukyus, and the staff of Okinawa Churaumi Aquarium. We thank T. Kuwamura, Y. Nakashima, K. Karino, T. Irie, M. Nonaka, H. Yamamoto, A. J. Heyward, and M. Morita for their comments and suggestions. We also thank R. A. Kinzie for comments on the manuscript and A. Nishikawa for encouragement, help, and advice. We are very grateful to the 5 anonymous reviewers who helped improve the manuscript. This study was partially supported by the Japan Society for the Promotion of Science (Grants-In-Aid Nos. 16310158 and 18651112 to K.S.), and the 21st Century COE program of the University of the Ryukyus.

\section{LITERATURE CITED}

Babcock RC (1991) Comparative demography of three species of scleractinian corals using age- and size-dependent classifications. Ecol Monogr 1:225-244

Bone EK, Keough MJ (2005) Responses to damage in an arborescent bryozoan: effects of injury location. J Exp Mar Biol Ecol 324:127-140

Brickner I, Oren U, Frank U, Loya Y (2006) Energy integration between the solitary polyps of the clonal coral Lobophyllia corymbosa. J Exp Biol 209:1690-1695 
Connell J (1973) Population ecology of reef-building corals. In: Jones OA, Endean R (eds) Biology and geology of coral reefs. Academic Press, New York, p 205-245

Fine M, Oren U, Loya Y (2002) Bleaching effect on regeneration and resource translocation in the coral Oculina patagonica. Mar Ecol Prog Ser 234:119-125

Gateno D, Rinkevich B (2003) Coral polyp budding is probably promoted by a canalized ratio of two morphometric fields. Mar Biol 142:971-973

Grubbs F (1969) Procedures for detecting outlying observations in samples. Technometrics 11:1-21

Hall VR, Hughes TP (1996) Reproductive strategies of modular organisms: comparative studies of reef-building corals. Ecology 77:950-963

Hayashibara T, Shimoike K, Kimura T, Hosaka S, Heyward A, Harrison P, Kudo K, Omori M (1993) Patterns of coral spawning at Akajima Island, Okinawa, Japan. Mar Ecol Prog Ser 101:253-262

Heyward A, Yamazato K, Yeemin T, Minei M (1987) Sexual reproduction of corals in Okinawa. Galaxea 6:331-343

Hughes TP, Connell J (1987) Population dynamics based on size or age? A reef-coral analysis. Am Nat 129:818-829

Hughes TP, Jackson JBC (1980) Do corals lie about their age? Some demographic consequences of partial mortality, fission and fusion. Science 209:713-715

Hughes TP, Jackson JBC (1985) Population dynamics and life histories of foliaceous corals. Ecol Monogr 55:141-166

Hurlbert S (1984) Pseudoreplication and the design of ecological field experiments. Ecol Monogr 54:187-211

Kojis BL, Quinn NJ (1981) Aspects of sexual reproduction and larval development in the shallow water hermatypic coral, Goniastrea australensis. Bull Mar Sci 31:558-573

Kojis B, Quinn NJ (1985) Puberty in Goniastrea favulus: age or size limited. Proc 5th Int Coral Reef Symp 4:289-293

Little R, Rubin D (1987) Statistical analysis with missing data. John Wiley \& Sons, New York

Loya Y (1976a) The Red Sea coral Stylophora pistillata is an $\mathrm{r}$ strategist. Nature 259:478-480

Loya Y (1976b) Skeletal regeneration in a Red Sea scleractinian coral population. Nature 261:490-491

Muko S, Sakai K, Iwasa Y (2001) Size distribution dynamics for a marine sessile organism with space-limitation in growth and recruitment: application to a coral population. J Anim Ecol 70:579-589

Nishihira M, Veron JEN (1995) Hermatypic corals of Japan.

Editorial responsibility: Otto Kinne,

Oldendorf/Luhe, Germany
Kaijyusha, Tokyo (in Japanese)

Okubo N, Motokawa T, Omori M (2007) When fragmented coral spawn? Effect of size and timing on survivorship and fecundity of fragmentation in Acropora formosa. Mar Biol 151:353-363

Oren U, Rinkevich B, Loya Y (1997) Oriented intra-colonial transport of ${ }^{14} \mathrm{C}$ labeled materials during coral regeneration. Mar Ecol Prog Ser 161:117-122

Oren U, Brickner I, Loya Y (1998) Prudent sessile feeding by the corallivore snail Coralliophila violacea on coral energy sinks. Proc R Soc Lond B 265:2043-2050

Roff DA (1992) The evolution of life histories: theory and analysis. Chapman \& Hall, New York

Sakai K (1997) Gametogenesis, spawning, and planula brooding by the reef coral Goniastrea aspera (Scleractinia) in Okinawa, Japan. Mar Ecol Prog Ser 151:67-72

Sakai K (1998a) Effect of colony size, polyp size, and budding mode on egg production in a colonial coral. Biol Bull (Woods Hole) 195:319-325

Sakai K (1998b) Delayed maturation in the colonial coral Goniastrea aspera (Scleractinia): whole-colony mortality, colony growth and polyp egg production. Res Popul Ecol 40: $287-292$

Searle S (1987) Linear models for unbalanced data. John Wiley \& Sons, New York

Sibly R, Calow P (1986) Physiological ecology of animals: an evolutionary approach. Blackwell Scientific, Oxford

Smith LD, Hughes TP (1999) An experimental assessment of survival, re-attachment and fecundity of coral fragments. J Exp Mar Biol Ecol 235:147-164

Soong K (1993) Colony size as a species character in massive reef corals. Coral Reefs 12:77-83

Soong K, Lang JC (1992) Reproduction integration on reef corals. Biol Bull (Woods Hole) 183:418-431

Stearns SC (1992) The evolution of life histories. Oxford University Press, New York

Stefansky W (1972) Rejecting outliers in factorial designs. Technometrics 14:469-479

Szmant AM (1986) Reproductive ecology of Caribbean reef corals. Coral Reefs 5:43-53

Szmant-Froelich A (1985) The effect of colony size on the reproductive ability of the caribbean coral Montastrea annularis. Proc 5th Int Coral Reef Symp 4:295-300

Veron JEN (2000) Corals of the world. Australian Institute of Marine Science, Townsville

Submitted: April 12, 2007; Accepted: August 22, 2007

Proofs received from author(s): January 15, 2008 